Article

\title{
Blockchain-Based Traceability for Anti-Counterfeit in Cross-Border E-Commerce Transactions
}

\author{
Heongu Lee ${ }^{1, *}$ and Changhak Yeon ${ }^{2}$ \\ 1 Office of Strategic R\&D Planning, Korea Evaluation Institute of Industrial Technology (KEIT), \\ Seoul 110, Korea \\ 2 BlockOdyssey Ltd., Seoul 110, Korea; chyeon@blockodyssey.io \\ * Correspondence: janelee@keit.re.kr or janeleeicu@gmail.com
}

Citation: Lee, H.; Yeon, C.

Blockchain-Based Traceability for Anti-Counterfeit in Cross-Border E-Commerce Transactions. Sustainability 2021, 13, 11057. https:/ / doi.org/10.3390/su131911057

Academic Editors:

Gwo-Hshiung Tzeng, Kao-Yi Shen and Shih-Wei Liao

Received: 9 August 2021

Accepted: 28 September 2021

Published: 6 October 2021

Publisher's Note: MDPI stays neutral with regard to jurisdictional claims in published maps and institutional affiliations.

\begin{abstract}
Cross-border e-commerce, involving international product transactions via online and mobile platforms, is growing at a dramatic rate around the globe. One of the main concerns of brand firms is preventing counterfeit products from being sold under their names on e-commerce platforms. Counterfeit goods not only create economic losses to both the supply and demand sides, but also undermine efforts to improve sustainability. Proliferating counterfeits harm the brands of supply firms and trust in selling e-commerce platforms. In addition, they discourage participants in the supply chain from investing in social and environmental sustainability. If end-customers have access to detailed and comprehensive product information with a traceability system that can help overcome information uncertainty and asymmetry, losses can be prevented. The result of the pilot test has shown that securely shared in-depth product information among supply chain stakeholders from the supply side to end-customers can help prevent counterfeit goods from proliferating further by enabling consumers to determine the authenticity of products and report forgeries before paying.
\end{abstract}

Keywords: information asymmetry; cross-border e-commerce; traceability; counterfeiting prevention; encrypted QR code; Blockchain; PoET algorithm; Sawtooth system

\section{Introduction}

The growing use of the Internet has disrupted many existing business models and led to the introduction of innovative new businesses, such as e-commerce, which is a key feature of the modern digital economy. As cross-border trade volume has increased, global transactions and government enforcement has compelled many e-commerce platforms to comply with regulatory mandates. However, when it comes to cross-border e-commerce, platforms frequently fail to monitor agents, distributors, business partners, supply intermediaries, and other third-party intermediaries because of the complexity of supply and distribution channels [1]. The lack of supply side traceability reduces customers' trust in platforms, resulting in economic and reputation damage to stakeholders.

A supply chain is a complex network in which a variety of participants coordinate tasks and exchange information [2]. After SCM systems were first introduced in 2000, most firms have adopted them to strategically manage the flow of goods, from raw materials to final products [3]. Despite rapidly increasing cross-border transactions and end-customers' desire to instantly confirm product origin, ingredients, and manufacturers, existing SCM methods, including manual data entries, have been unable to satisfy real-time data exchanges [4] while maintaining the data integrity of supply chains. Because of outdated SCM functions, inconsistent data taxonomy and ways of exchanging data, vague fears of product information leakage, and unknown threats [5], many participants in supply chains are reluctant to share their product data with end-customers.

In the meantime, as more consumers have become eco-conscious and understand how their buying decisions impact the environment, demand for more comprehensive information about products has rapidly increased. Both business and personal customers 
who buy consumable goods via e-commerce platforms frequently ask for information on raw material suppliers, ingredients, and distribution channels of departure countries, valuing such transparency [6] more than ever before. The growing sensitivity of consumers to supply chain data and information is a positive step from the perspective of sustainability, because fake information and the uncontrolled distribution of counterfeit goods has undermined the efforts of firms who attempt to follow the rules in their supply chains, in the end, consumers have to pay a higher social and environmental price [7].

While brand firms have worked to establish a positive name and values by following sustainable and ecological business practices, a massive number of counterfeiters have been detected as the volume of cross-border transactions has grown. The case of Asiago [8] is an example. Not only the food industry, but in many other industries, including pharmaceuticals, luxuries, and apparel, counterfeit products harm companies' trustworthiness and cost customers' money and even health. Since forged products can be mistaken for the originals in terms of appearance, they are subject to strict regulation and checks. However, more advanced technological solutions are also imperative, considering the volume of cross-border e-commerce transactions.

For instance, as concerns about food security have increased, a food traceability system based on Blockchain technology was developed [9] that can trace the entire supply chain in real time, as well as eliminate the dubious intervention of middlemen. In many Blockchain feasibility tests around the world, it has been reported that Blockchain technology can effectively filter fraudulent interventions and counterfeit goods, thanks to its technological characteristics, such as digital signature and validation [10]. As the supply chains of firms in the global e-commerce environment have become increasingly disaggregated, moving away from domestic control [6], brand value and profits of them can be increasingly damaged by forgery behaviors. Brand firms, including manufacturers and platforms, are now seeking ways to protect their value in securely sharing product information across their direct and indirect value chains.

While there is a growing literature on Blockchain and its potential to promote sustainability by boosting traceability and transparency, and better coordinate complex global value chains [11], it is still rare to find concrete examples showing how best to exploit Blockchain characteristics, traceability, and transparency, in order to prevent the distribution of counterfeit goods.

It is argued in this paper that Blockchain has a digital recording mechanism suited for dealing with the enhanced complexity of supply chains. In addition, it is suggested that complementing Blockchain with authentication tags enables product information to be securely shared among supply chains stakeholders and end-customers, thus significantly removing counterfeit goods from e-commerce platforms.

The research focuses on how to exploit the technological features of Blockchain in order to solve information uncertainty and asymmetry resulting in counterfeiting and economic losses of the weakest SCM participants including the end-customers within the research scope of green SCM since counterfeiting harms firms, particularly those who have invested considerable amounts of technological and economic resources in efforts to comply with sustainable and ecological rules and standards. The rest of the paper is organized as follows. Section 2 reviews Blockchain technology and its applications in the context of green supply chain management. Section 3 explores the system design and the pilot test results of cross-border traceability system based on Blockchain and complementary technologies. It introduces the system configurations for cross-border data sharing with end-customers, and Blockchain's complementary technologies, such as encrypted QR Codes and PoET consensus algorithms. Section 4 discusses the results of the pilot test and the benefits and limitations of the proposed system. It analyzes and evaluates the performance of the system based on various factors, including hardware, block timing, network latency, and the confirmation of product information abroad. Section 5 concludes the work and the contributions and proposes possible avenues for future research. 


\section{Theoretical Background}

\subsection{Counterfeiting from the Perspective of Green SCM}

\subsubsection{Green Supply Chain Management}

Since 1994, when the first retail Internet transaction was successfully performed [12], global e-commerce sales have annually increased by almost 30 percent [13]. In 2019, worldwide retail e-commerce sales amounted to USD 3.53 trillion [14]. This phenomenon is mainly due to giant platforms such as Amazon, Alibaba, JD.com, and Pinduoduo [15]. As online shopping has become one of the most popular retail activities in the COVID-19 era, the business frontiers of e-commerce have naturally grown beyond domestic borders [16-18]. Today, cross-border e-commerce is everywhere.

Cross-border e-commerce is a type of international e-commerce in which transactions are conducted via online and mobile platforms [19] across domestic borders. In a world where Internet-based transactions are common, managing business relationships is critical to the success of businesses, and a well-managed supply chain, which allows intra and interfirm integration, affects every aspect of business activity [3].

According to the Global Supply Chain Forum, supply chain management (hereinafter referred to as SCM) is defined as the integration of key business processes from end users through original suppliers who provide all the value, including products, services, and information, to supply chain participants [20]. SCM is the management of all of the value flows of those business relationships and is distinguished from logistics management in that it does not encompass suppliers who provide raw material to the manufacturer, or multiple layers of processes within and across companies outside the direct marketing processes [21]. However, if it is presumed that SCM encompasses all of the firms in the whole supply chain, from raw material provider to the end-customers, the dimensions of SCM can affect productivity [22]. For this reason, it is necessary for a firm to decide on who the primary SCM participants are [3] by adding critical values to the business processes.

Recently, as climate change has increasingly impacted daily life, the public has become more aware of environmental issues, and accordingly multinational manufacturing firms have become more concerned with managing their supply chains [23,24]. Operating without firm control over its own supply chain can impact corporate social responsibility, which negatively impacts product quality and innovation. From this perspective, scholars consider ecological consideration an important management factor of supply chain [25-27] and have called for green awareness in a variety of aspects including product and process design [28,29], manufacturing [27,30], and purchasing [31]. Customers and governments [32,33] have begun to raise more green issues and standards, in return more companies have started to incorporate green policies and efforts throughout their supply chains, such as eco-labeling and green advertising [34]. Even though such firms' green practices are basically business oriented in terms of market regulatory compliance, brand promotion, and competitive advantages, the ripple effect on the supply chain has influenced more SCM participants [22]. With the increasing awareness of social and environmental responsibility [35], green practices $[27,31,36]$ have been incorporated into the SCM of firms. Although it is argued that some green behaviors, such as green purchasing, have a negative effect on organizational performance [25], practicing green activities usually increases the environmental and financial performance $[37,38]$ of firms due to the well-monitored supply chains. There is little doubt that sustainable and green practices are value adding to business, and opening business opportunities, especially for consumer brands [39].

It is no doubt that green supply chain management (hereinafter, referred to as GSCM) is related to firms' comprehensive efforts to improve performance along their supply chain [40]. Thus, GSCM is broad and holistic [22]. It is not only about greening primary business processes with respect to environmental issues, but also includes social factors such as labor and human resource practices [41] and many other CSR practices [23-25] including diversity, human rights, and safety issues [36]. While successful GSCM cases can be found in many industries, from consumer goods, foods [39], and pharmaceuticals [24,40] 
to automobiles [42], it is also undeniable that firms' efforts to pursue GSCM are frequently undermined by a variety of offensive behaviors, including counterfeiting and forgeries.

\subsubsection{Counterfeiting Issues}

Coupang, founded in 2010 and funded by the SoftBank Vision Fund with about 2 billion dollars in 2018, is currently the largest e-commerce retailer in South Korea. South Korea has one of the highest rates of Internet penetration and smartphone adoption in the world, and hence has become a lucrative market for e-commerce platforms [43]. As the trading volume of Coupang, including cross-border transactions via its open market, has dramatically increased, customers' outcry over counterfeit goods has also rapidly grown, in spite of its sizable investment in SCM innovations and unrivaled consumer offerings.

Counterfeit issues plague various industries including manufacturing [44-46] foods [8,9,47], dairies [48], pharmaceuticals [49-54], 3D-printed goods [55], and luxuries $[56,57]$ and also degrade the credibility of intangible assets $[10,58,59]$ including a variety of certifications such as HACCP, organic ingredients, energy saving, eco marks, fair trade, anti-child labor, Forest Stewardship Council (FSC), Marine Stewardship Council (MSC), and many others. Nonetheless, it is still rare to find preemptive measures to cope with consumer losses caused by buying fake goods.

In most cases, e-commerce customers rarely have the ability to know in advance whether they are buying genuine goods or not, and thus tend to rely on e-commerce platforms' fame and credibility. On the e-commerce firms' side, they have made efforts to drive fake products off their platforms and SCM, by hiring dedicated personnel, by operating a $24 \mathrm{~h}$ monitoring system, and by setting sanction standards for the sale of counterfeit goods. For example, if a product being sold is found to be counterfeit, the sellers are expelled from the platform for good.

However, these measures are far from ex ante prevention capable of prescreening before payment. Fake goods are frequently marked with "looking like genuine" barcodes which makes it difficult and takes a while for customers and the firms to acknowledge and judge fakeness. Even though it is a criminal offense under the criminal laws of many countries when sellers deceive consumers with fake products, counterfeit goods are becoming a worse headache in online transactions. Not only institutional measures but also technological methods are required to prevent forgery behaviors, since counterfeiting is found across $\mathrm{SCM}$, from raw materials to marketing, and from country to country, across e-commerce platforms.

In the case of Shopify, a newly rising e-commerce firm [46] in the US, faulty goods problems have increased as fast as its growth rate, and the consequences have gone beyond damaging the brands and reputations of the original firms, to even putting people's lives in danger [48]. Despite these consequences, counterfeiting has become a fast-growing lucrative business of more than USD 600 billion value annually [49]. The International Chamber of Commerce estimates that the size of counterfeiting and piracy will reach USD 4.2 trillion by 2022. In the case of pharmaceutical counterfeiting, the WHO estimates that 10 [51] to 30 percent of drugs [53] on the global market are counterfeit, and the situation is particularly serious in developing countries [49,51-53] due to the invisibility of supply chain systems.

Growing forgery behavior is not only problematic in the food and pharmaceutical industries but also in many unexpected industries, including additive manufacturing [55], luxury fashion [56], and others [57]. It leads to a devaluing and economic loss of legitimate firms, what it is worse is that the raw materials or ingredients are from unknown sources [52], and faulty foods, dairies, and drugs can pose a significant threat to people's lives [8], with multiple fatal accidents [48,50,54] from industrial dyes, and other tainted and contaminated ingredients [9].

At the same time, counterfeiting documents including welfare vouchers [58], insurance papers [59,60], and L/C [10] have also created serious social distrust [8,9] of the integrity of policies and institutions. Fake certificates undermine the sustainability efforts of original 
brands [47] and the credibility of public institutions at the same time, since inappropriate goods can never meet environmental regulations or supervision guidelines.

As forgery behaviors have proliferated, customer awareness has been accordingly raised, and today more people want transparency about the processed and agricultural products they consume [61]. Product labels and manufacturing and logistics information [47] have become matters of concern, and consumers have started to ask for transparent traceability across the SCM, especially in crossing borders in the e-commerce world.

Manufacturing firms and e-commerce platforms also want to protect their brand value and profits by preventing illegal events associated with the supply chain from the beginning [5] in spite of rather slow transactions and low visibility with the current SCM [45].

Regarding the counterfeiting of tangible and intangible products, a variety of studies have suggested that Blockchain features have useful technological characteristics for enhancing visibility and transparency [62] in complex multi-level SCMs, since all the transactions in the complex SCM layers can be captured and recorded. It is also known that Blockchain can effectively reduce risks regarding fraud and counterfeit goods [2] and securely record transactions [45] by minimizing human interventions.

\subsection{Key Features and Applications of Blockchain for Supply Chain}

Blockchain is a decentralized and distributed public digital ledger for recording data and information, or in other words, transactions, in blocks. In principle, written transactions on blocks are irreversible, and cannot be changed without changing all the previously written transactions on prior blocks. As a result, ever since its basic concept and disruptive potential were introduced with Satoshi Nakamoto's paper "Bitcoin: A Peer-to-Peer Electronic Cash System" in 2008, research and experiments with Blockchain as a technology of trust have sharply increased across industries [63] including distributions and logistics, financial services, and healthcare.

In the early period, many applications were centered in the financial area, including digital assets, remittance and online payment, smart contracts, and reputation systems [64]. While Bitcoin is an innovation for financial services based on Blockchain [65], Blockchain is a general-purpose technology and can be categorized into public, private, consortium [65], or hybrid [64].

Public Blockchain is an open, non-restrictive, and distributed ledger system not requiring permission. Bitcoin, Litecoin, and Ethereum are typical examples. Anyone with access to the Internet can be a node with authority for mining, accessing records and verifying transactions. Because there is no centralized entity in charge, decision-making activities like verifying transactions require consensus algorithms.

In contrast, private Blockchain is a closed, restrictive, and permissioned system. One cannot join the system without an invitation from the controlling node which is in charge of the private system, and each node has a different level of accessibility and a specific authority for creating, viewing, and verifying transactions. Ripple works as both a cryptocurrency and a digital payment network, and unlike Bitcoin, anyone who wants to become a node in the Ripple network needs permission. Ripple is usually regarded as a private Blockchain although all the nodes on the network conduct polls and decide whether a transaction is valid and authentic.

While a private Blockchain is controlled by one organization, a consortium or federated Blockchain is managed by more than one organization, and a few selected nodes are authorized for verifying transactions and overseeing the consensus process. Hyperledger Fabric, Hyperledger Sawtooth, Corda, and Quorum are representative examples. Among them, Hyperledger has strong business applicability and has been widely tested. In the pilot test, Hyperledger Sawtooth is adopted, in which PoET (Proof of Elapsed Time) is used as a consensus mechanism. Sawtooth is an open-source code in Hyperledger driven by Intel. Its high modularity, by separating the core system from the application domains, makes application development convenient. To improve latency, throughput, and scalability, Intel 
has proposed utilizing the trusted computing of CPU, which can offer a Trusted Execution Environment (TEE) where executions are performed without tampering from fallacies.

Hybrid Blockchain has both public and private features. Blockchain systems for smart homes can be private as well as public. It is private to ensure the security of each home Internet of Things (IoT) devices, but at the same time needs to connect to a public Blockchain for digital payments. Finally, a hybrid Blockchain can consist of a public Blockchain, as Mainnet, and multiple private Blockchains, so-called sidechains. Hdac, Interchain, and ICON are some examples of hybrid Blockchains.

Among the many features of Blockchain, decentralization is the most typical and critical [64], whether public or private. Blockchain developers have tried to distribute the dominance and power of a central agency in order to avoid issues such as high cost, biases, bottlenecks, and corruption problems coming from centrality. Unlike conventional systems, Blockchain no longer requires surveillance by a third party [65] to verify transactions [66]. Instead, peer-to-peer communication assumes the role of the third party, where peers on the network share the data and information of all the other nodes [11]. While transactional data and information are visible to anyone on the network, unlimited communication coming from decentralization necessitates the anonymity [64] and pseudonymity $[11,66]$ of nodes.

Decentralization also requires consensus algorithms [64] for performing decisionmaking activities. A variety of consensus algorithms $[47,65]$ have been tested and improved, including PoW, PoS, DPOS, dBFT, PBFT, Ripple, Tendermint, and PoET. Selecting the right consensus algorithm is essential for a Blockchain system because the system has to effectively prevent fallacy-users who try to intercept system control and make wrong choices that can be associated with high energy usage and poor performance. The PoET consensus algorithm is adopted for the pilot test since it can ensure a level of security similar to PoW (Proof-of-Work) by using the CPU feature and can reduce energy usage with a competitive hashing operation compared with PoW.

PoET is based on Software Guard Extensions (SGX), Intel's trusted computing platform, which helps the node creating a block to generate a proof of the waiting time. Compared with PoW, PoET is known for less computational workload while creating and keeping high fairness with "one CPU one vote" even though trusted computing technologies including SGX may not guarantee 100 percent reliability. Since there were insufficient empirical results for Hyper Sawtooth and the PoET algorithm [67], we would like to suggest that multiple pilot tests are necessary to validate their feasibility for business applications.

Decentralization and peer-to-peer communication in Blockchain make reverse transactions almost impossible [11]. Once a transaction is written on a block, the records cannot be changed since every block is linked to the previous one up to a head block. In SCM, these features work positively [68] in that the irreversible traceability can be used to address transaction transparency and accuracy, as well as smart contracts [64]. For smart contracts, Blockchain transactions can be executed with specifically tied (or programmed) computational logic. The terms of a contract among nodes can be programmed in advance and embedded in the Blockchian system as a smart contract, which provides a programmed transaction protocol. Smart contracts can be utilized in various fields including finance, utilities, IoT $[66,69]$ loyalty management, SCM and many others.

The technological features of Blockchain that are related to the sharing, openness, and decentralization of data and information among nodes make it unique and innovative, especially in the area of SCM [51,70,71]. A group of researchers have found that Blockchain can prove the trustworthiness of products and documents based on the traceability feature $[45,52,68,70]$. Due to the ever-increasing complexity of supply chain management has also increased demand for transparent operations from the perspective of social and environmental sustainability [70], and Blockchain's complete traceability of end-to-end SCM has been welcomed by practitioners and developers as the right tool for SCM transparency.

In the meantime, tagging technologies, such as barcodes, QRs, RFID (900 MHz), and NFC (13.56 MHz) have long been widely adopted in order to prevent counterfeit 
and to provide traceability. Recently there have been increasing experiments to combine them with Blockchains. Those trials have successfully verified that inventories can be completely traceable, while enhancing aspects of operating performance such as reduced stock-outs, shortened lead-times, and improvement in operating cost [52]. In some public health projects designed to prevent counterfeit medicines [70], RFID tags were combined with Blockchain and provided object status data such as tablet information [4] with realtime visibility. The combination of Blockchain and QR code, a two-dimensional barcode introduced by Denso-Wave in 1994, has also been widely tested for traceable SCM in many countries. QR codes are cheap and easy to use, since they can be easily printed on individual assets and are scannable by mobile apps.

However, it also argued that Blockchain's advantageous SCM features work negatively in business circumstances. Because it is virtually impossible to intentionally operate (delete, insert, move forward and backward) transactions once the transactions are written on blocks, a sort of rigidity [64] is intrinsic. Accordingly, correcting entry errors and inaccurate data is almost impossible, which means that incorrect data and information can remain in Blockchains permanently [63]. In addition, the slow processing speed which results from checking all the previous blocks for each transaction considerably limits scalability. It is still necessary to overcome constraints in throughput, latency, and scalability when compared with the existing centralized systems, in which, for example, an average of 5000 credit-card transactions per second can be handled [70].

Counterfeiting is a growing challenge in supply chain management as trading becomes far more complex [45] and the volume of e-commerce based on digital technologies skyrockets. Not only tangible products such as agricultural produce [9], food [47], and medicines $[49,50]$ but also intangible products and documents $[53,55,56,58,59]$ are the objects of counterfeiting. Blockchain has been broadly tested as an alternative to existing anti-counterfeiting systems by adding systemic traceability. For example, BlockVerify with NFC tags offers Blockchain-based anti-counterfeit solutions for pharmaceuticals, luxuries, and electronics [57].

In enterprise-level Blockchain initiatives driven by multinational consumer firms and retailers, traceability has been enhanced without harming interoperability with legacy systems such as ERP (enterprise resource planning) systems. Walmart partnered with IBM [45] and has successfully completed a traceability pilot, tracking the origins of pork and mangoes, and now it traces the origin of more than 25 products, with plans to expand to all fresh greens. To track fresh foods and produce, Blockchain needs to interoperate and be incorporated with existing cold-chain systems, which usually consist of RFID tagged refrigerated containers and ERP. Blocks may record the temperature, traffic times, and verify authenticity of products by continuously recording product history.

Blockchain has also been applied for monitoring illegal labor practices such as child labor in mining [52]. Ridesharing firms such as Arcade City [64] have adopted it to track personal reputations that can be easily forged. For energy grids and Internet of Things [71] networks, security is so critical that Blockchain is frequently employed as a secure backbone as well as a billing system. VeChain with NFC tags [68] was developed to fight counterfeiting in fashion apparel, by letting consumers verify product information with mobile apps that communicate with NFC tags placed inside each item. It was found that standardizing traceability processes, system interfaces [68], and a good degree of interoperability with legacy systems are significant. Keeping this in mind, we tried to find the best trade-off among system configurations for traceability, interfaces, interoperability, and system cost.

\section{A Systemic Methodology for Anti-Counterfeiting in E-Commerce Environment 3.1. System Configuration}

Our research question lies in "how to overcome information uncertainty and asymmetry that bring about counterfeiting behaviors with technological innovation". From this perspective, the systemic methodology how to overcome information uncertainty and 
asymmetry for anti-counterfeiting is basically based on private Blockchain since Blockchain is proven as an effective innovation to enhance traceability problems in SCM in a variety of prior research.

While private Blockchain tends to widely adopt PBFT (Practical Byzantine Fault Tolerance) possibly due to IBM's brand and dominance, it was tried to find a viable system configuration that includes a consensus algorithm, smart contract, and data format for cross-border logistics. It is very difficult to change or update nodes in PBFT, thus the rigidity of PBFT is a disadvantage for logistics traceability where node changes might be frequent, as distribution channels and participants come and go in the value chain, creating sales outlets or creating new customers. On the other hand, the PoET consensus algorithm is based on elapsed time proof; therefore it can support many changes with less electric power even though it works similarly to proof-of-work (PoW). In PoET, the random waited time is partially dependent on the CPU performance. The higher the CPU performance, the faster the processing speed and the higher the probability of becoming a block producer (BP).

If configuring a pilot system based on Hyperledger Sawtooth, which is a Blockchain platform using the PoET consensus algorithm, an Intel CPU supporting the SGX environment can be an individual node and ensure elapsed time provided by Trusted Execution Environment (TEE). In other words, the elapsed time proof algorithm effectively operates in any Blockchain system consisting of Intel CPUs that can scale up to thousands of nodes and support SGX. Accordingly, the HyperLegder Sawtooth platform and PoET consensus algorithm were adopted. It was expected that interface issues because the system was configurated with HyerLedger Sawtooth and PoET, different from the counterpart system which is based on HyperLedger Fablic and PoW. For this it was decided to establish API server called "MiddleReceiver" between two different Blockchain systems.

The current Blockchain system can only search and access data based on key indexing, which means if real-time statistics and filters are used, it is necessary to check all the data of the entire Blockchain ledger again for every transaction. In other words, if a system is configured that stores and retrieves all the data in Blockchain, it can check the status only at a specific time, thus additional functions including statistic results are not possible. In order to set up an effective product authentication system, a variety of product-related information such as product origins, statistics, and distribution channels must be openly shared among stakeholders on the value chain. To this end, the existing simple BlockchainApplication (DApp) structure shown in Figure 1a may not be a viable a solution. The system should have specific logics that periodically record the essential raw data whose integrity and reliability are guaranteed in the Blockchain. They should store statistical information in a separate database, and then periodically verify data integrity between the Blockchain and database. The configuration is shown in Figure $1 \mathrm{~b}$.

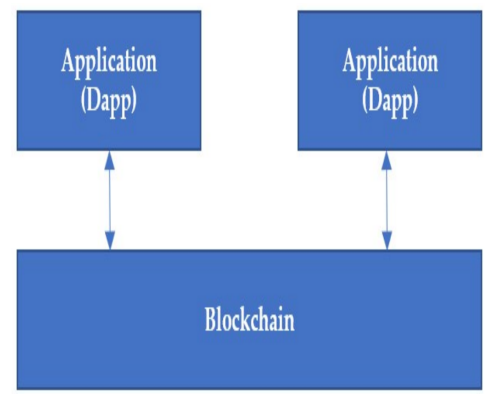

(a)

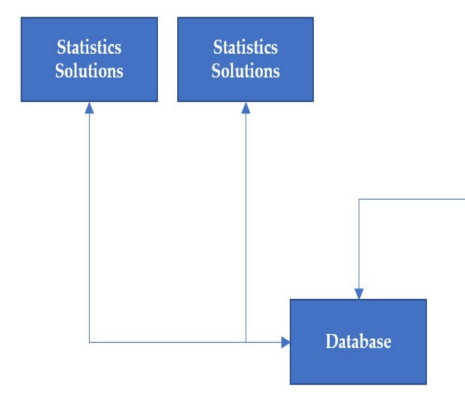

(b)

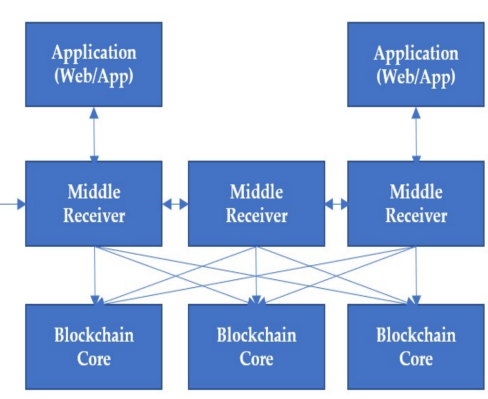

Figure 1. (a) Blockchain-DApp interface. (b) Blockchain-database interface.

In addition, it is required to set up a system that maintains decentralization as much as possible without compromising the reliability and integrity of information. At the same time, it should provide functions and transaction speed suitable for cross-border 
logistics. Blockchain is frequently called a "Status Machine", technically, Status refers to "information stored" at a specific point in time. So, the status machine is a device that remembers the status of a specific object for a given period of time. The request to change the stored status is a "transaction". Blockchain technology was originally created for the safe payment of Bitcoins; therefore, most Blockchain structures are strongly related to payments; if node A sends 1 Bitcoin to node B, 1 Bitcoin of node A decreases. However, the status of logistics process is not intended to establish a balance, but to store data on warehousing, shipment, distribution, product release, store receipt, product sales, and so on. What is more, each company and each value chain can have various statuses. Therefore, transactions can also be defined using formats other than deposit and withdrawal. Since having an individual Blockchain system for every stakeholder would not make sense, it is necessary that a comprehensive status operation method can handle all the logistics. For this, the "State-Transition Diagram" is conceptualized shown in Figure 2a and smart contract setting in order to flexibly respond to multiple situations of on-chain transactions is seen in Figure $2 b$.

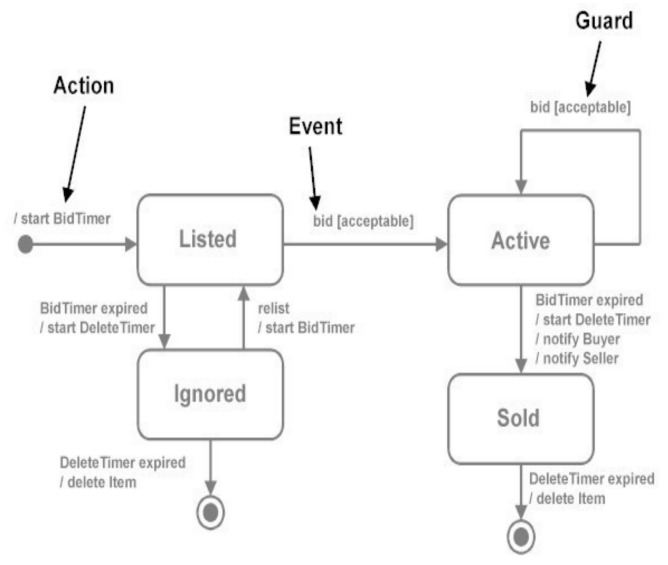

(a)

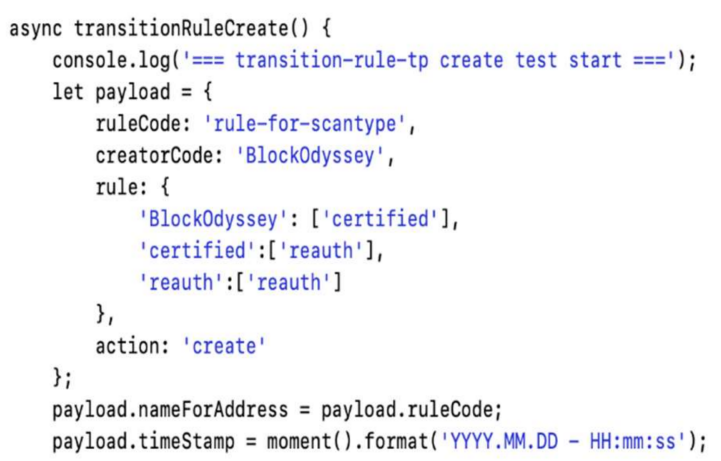

let commonClient $=$ new CommonClient(FAMILY_NAME, FAMILY_VERSION); let batchStatus $=$ await commonclient. send_transaction $($ payload $) ;$

(b)

Figure 2. State-transition: Create a status change rule, and respond according to the situation: (a) State-transition diagrams, (b) smart contract rule settings.

Finally, data collection interfaces were analyzed based on a standard logistics process in Figure 3 from raw material producers to end-customers. Barcodes, RFID, NFC, and other data-collecting interfaces were taken into consideration in order to set up the pilot system.

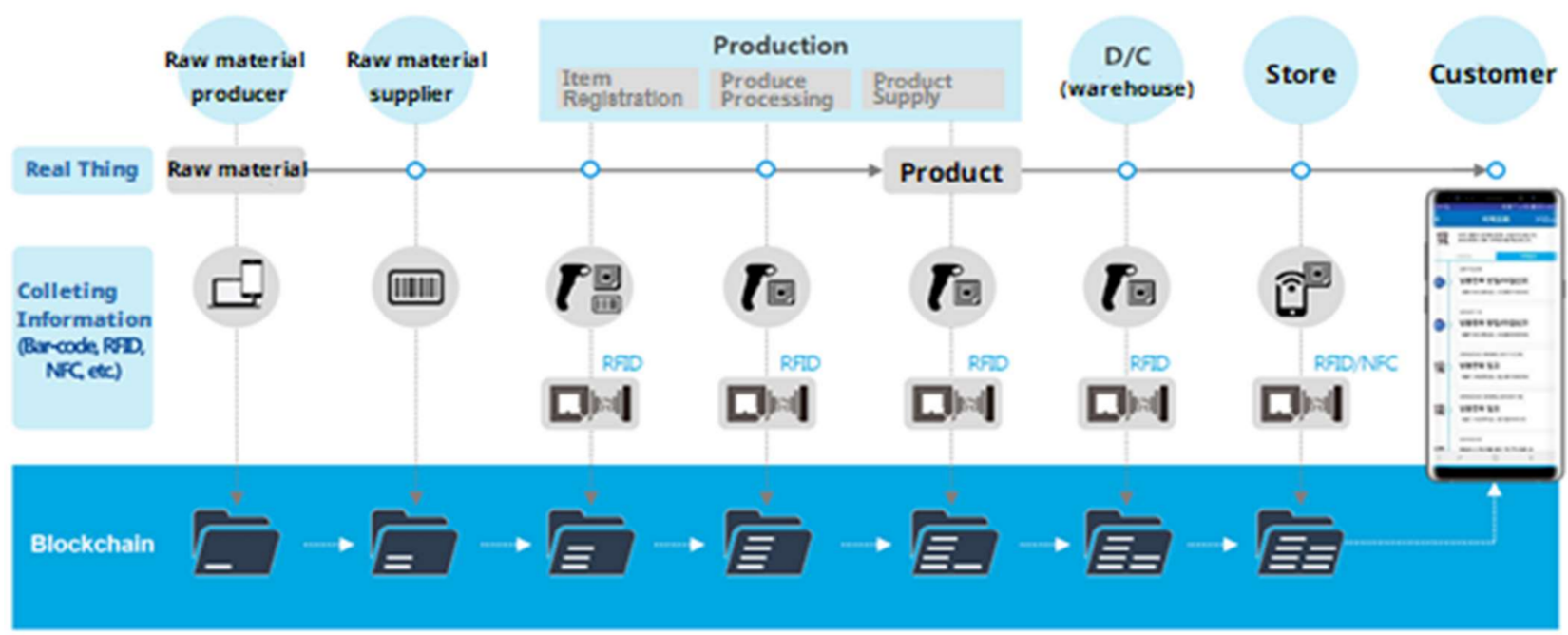

Figure 3. Data collection interface configuration based on standard logistics process. 


\subsection{Pseudo Data Test}

To test the traceability of domestic logistics and distribution before a cross-border pilot, first pseudo data sets were fabricated, then a Hyperledger Sawtooth system established having three full nodes as a Blockchain core which perform validation functions, and APIs which operate other business functions. The overseas counterpart is a Chinese e-commerce firm whose Blockchain platform is based on Hyperledger Fabric. For the interface between Hyperledger Sawtooth and Hyperledger Fabric in Figure 4, an API called MiddleReceiver was established in order to make REST API calls with cores and to perform additional functions.

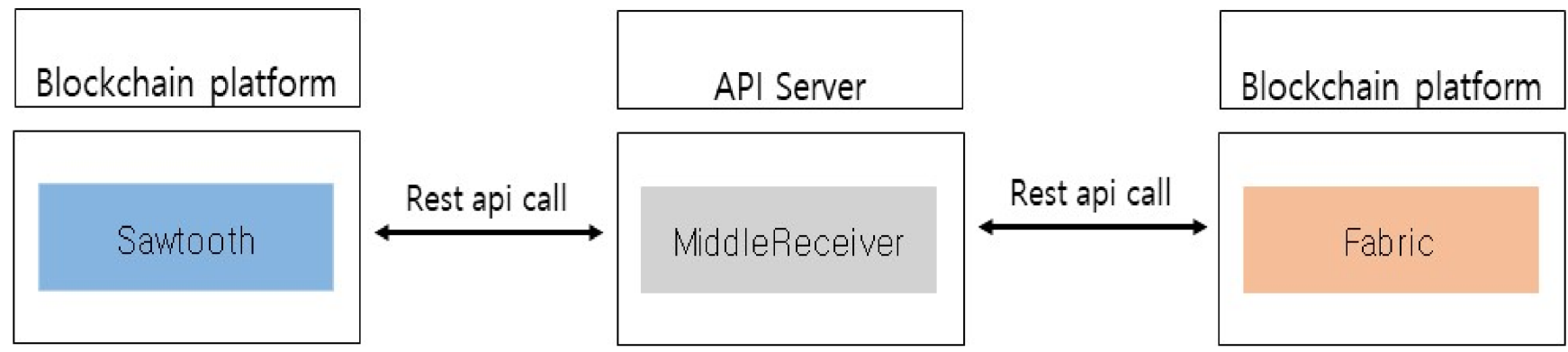

Figure 4. Interface based on MiddleReceiver between Sawtooh and Fabric.

In order to prevent counterfeiting in any process in the cross-border e-commerce environment by ensuring end-to-end traceability, one way might be to let local consumers confirm the originality and genuineness of products with their mobile phones. Like exemplified in Figure 5, anti-counterfeiting is possible by informing end-customers of full product information, including not only the country of origin and production history but also very detailed product-relevant information, such as customs clearance information, domestic distribution, and the logistics of departure and transit countries, with the product certificates of origin countries. However, consumers abroad should be provided with detailed and comprehensive product information at the appropriate level, which would not only satisfy traceability enough to block forgery behaviors, but fulfill the domestic regulations of the departure country (in this case, South Korea) about data sharing. Thus, the data architecture is carefully constructed seen in the following example for this purpose.

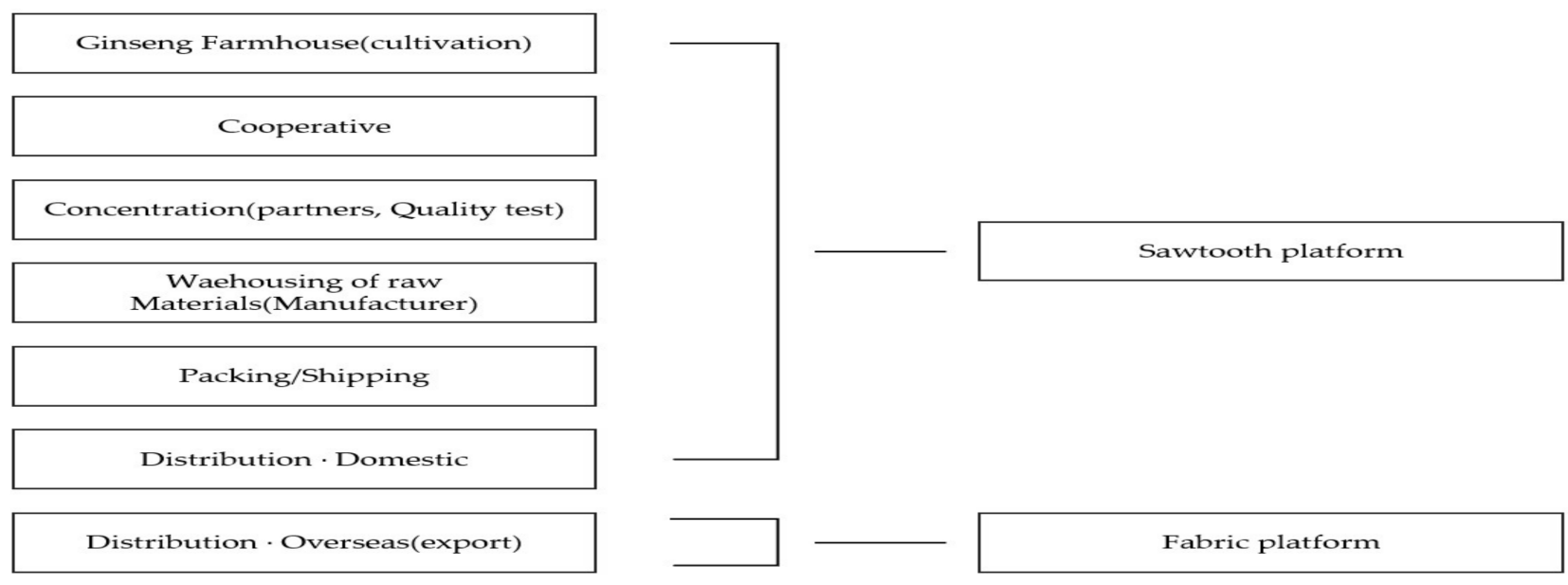

Figure 5. Expanded product information of a ginseng health drink. 
- Product Name: A ginseng health drink

- Sharing information: Cultivation place, processing and production, distribution, certificates, warehousing, etc.

Before the pilot test started with real product information, pseudo-data were fabricated seen in Figure 6 including origins, suppliers, manufacturing, distribution, logistics, and sales, and then tested the data flows between Sawtooth and Fabric. First, 88234215600016B and $688234215600016 \mathrm{D}$ were applied to the two finished products with pseudo-information after shipping inspection; the two codes were unique keys to identify objects without duplication. Then, the successful data interchange and flows between Sawtooth and Fabric were confirmed, as shown in Figure 7.

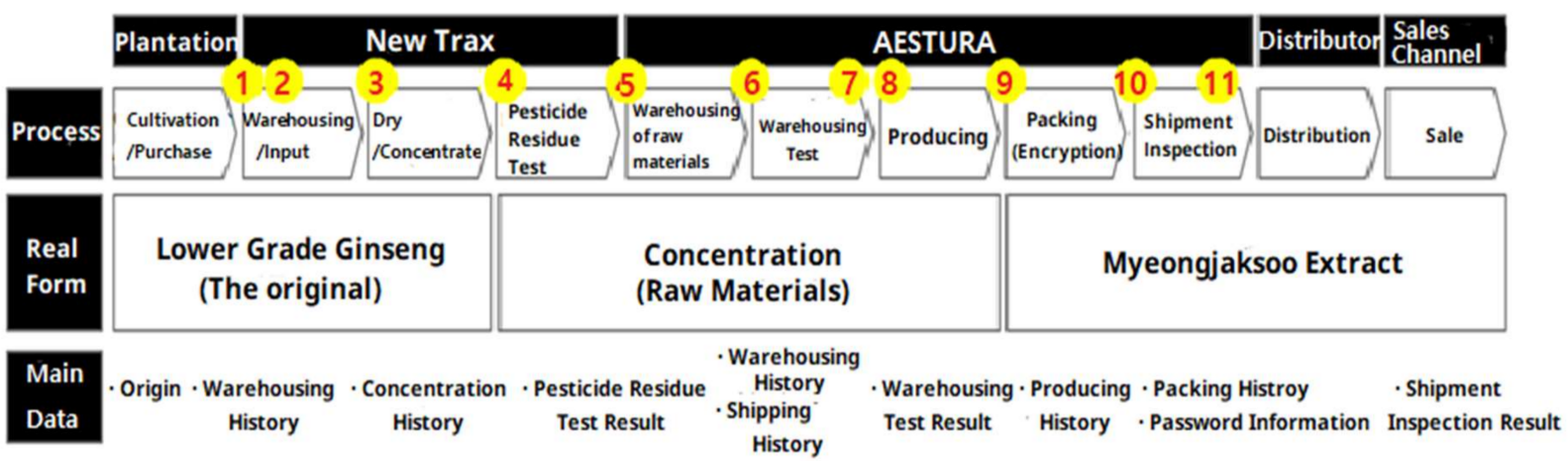

Figure 6. Expanded product information of the ginseng health drink.

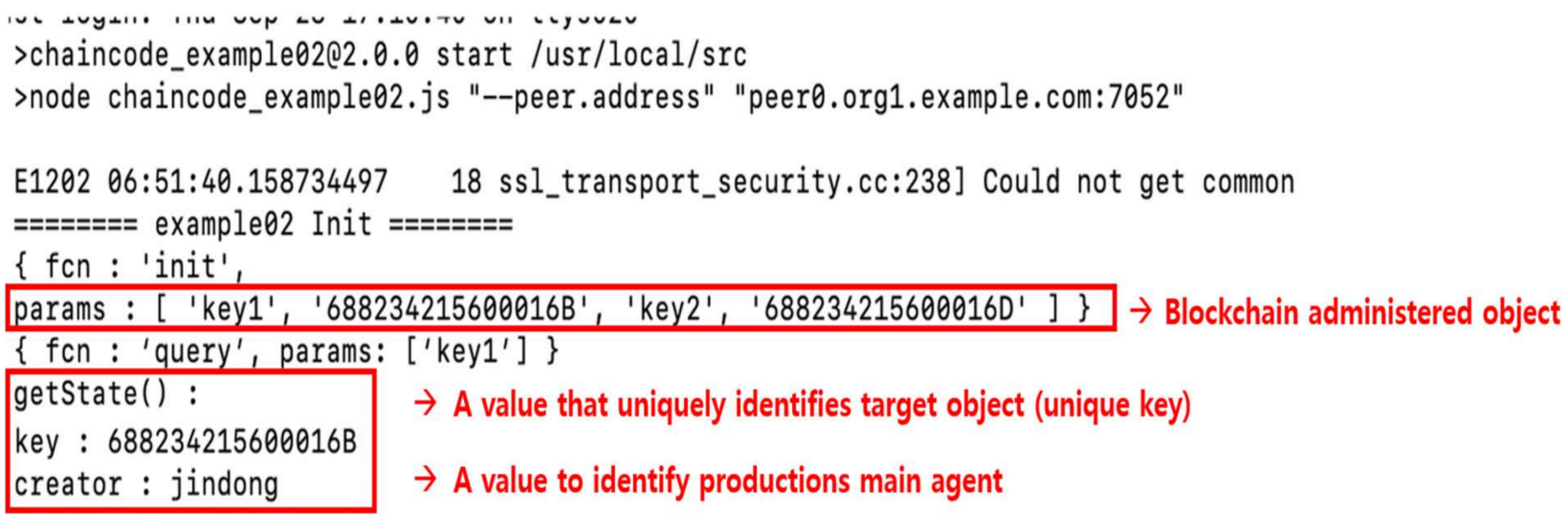

Figure 7. Private Blockchain data logs: Used as evidence of unchanging transactions afterwards.

\subsection{Real Business Data Test}

For the pilot test, two domestic manufacturing firms were contacted. One was a food and beverage firm and the other a cosmetics firm, and four pilot test products (one beverage and three cosmetics) were selected. From the test, it was confirmed that once an end-customer scanned an electronically signed QR code on a product shown in Figure 8a, if it had been authentic, the proof of authenticity of Figure $8 \mathrm{~b}$ was shown, and then relevant product information like Figure $8 \mathrm{c}$ would be displayed on the customer's mobile phone. When the end-customers scanned the QR code of a product, a forgery alert of Figure 9a will be displayed when the product $t$ is counterfeit. If the product was already registered as purchased by other customers, a duplication alert of Figure $9 \mathrm{~b}$ is displayed. Duplication also needs to be reported because it is assumed that duplication can occur when the product information is fabricated by other reasons except for entry mistakes. 
In case of an authentic product, detailed and comprehensive product information can be fetched as shown in Figure 10, some of detailed information is shown in Figure 11. For edible products, food falsification can result in significant health problems, therefore end-customers need to review relevant information as broadly as possible. Likewise, ingredients of beauty products also matter to users; thus, providing the information is beneficial, as seen in Figure 12. When it comes to e-commerce transactions, end-customers are usually in the vulnerable position of information asymmetry. Thus, it is tried via the test that open and safe sharing of product information, which are usually not shared with customers, can enable e-commerce participants including end-customers to avoid economic losses coming from information asymmetry in advance to some extent by helping them make a better choice in the unclear circumstance.
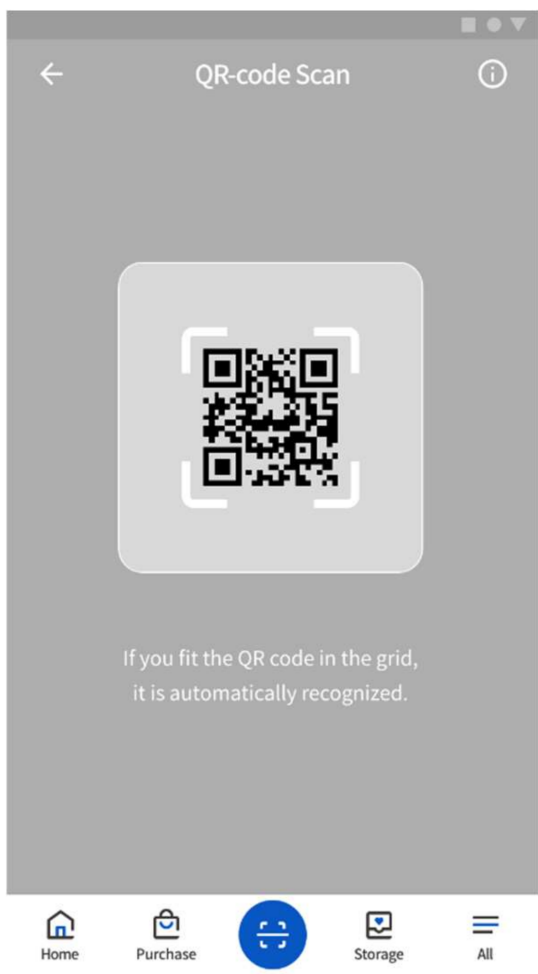

(a)

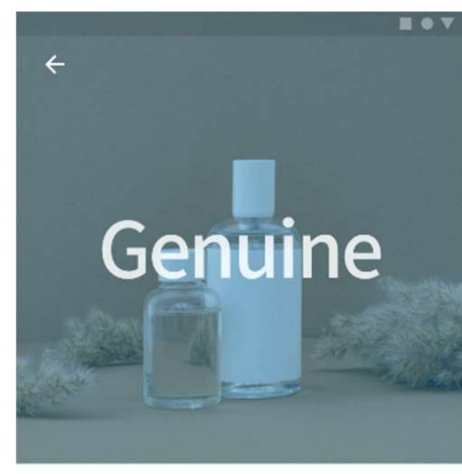

This product is genuine.

If the product is different from the certified product, please report it and contact the sales representative.

Tipi Cleansing Oli Dust Away Tipi

Mild high purity vegetable oil

A moist cleansing oil that can be used without worrying about eye irritation and irritation with 5 vegetable oils.

Deep cleansing to pores, daily sebum care

Contains freshly picked olives to purify the skin

Details

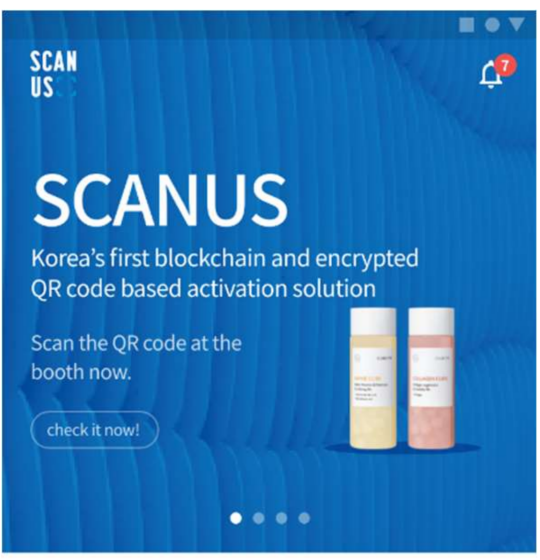

SCANUS affiliate brand

More

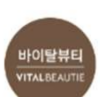

Amorepacific

Vital Beauty

Tipi Tipi

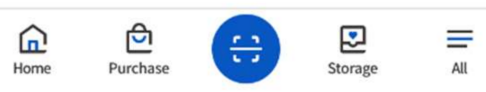

(c)

Figure 8. (a) QR scanning, (b) proof of authenticity, (c) more product information. 


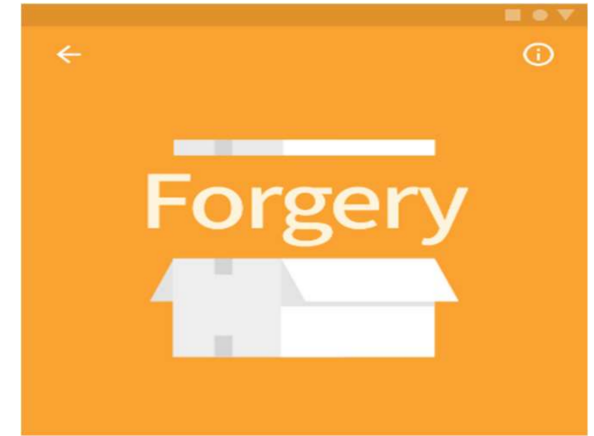

This QR code is not officially authenticated. If the affiliate brand is correct, check the product information below, and contact the person who purchased the product after reporting.

\begin{tabular}{l}
\hline Tipi \\
\hline Tipi Cream Care of Cica \\
\hline Coupang \\
If the brand and product are different, please choose your
\end{tabular}

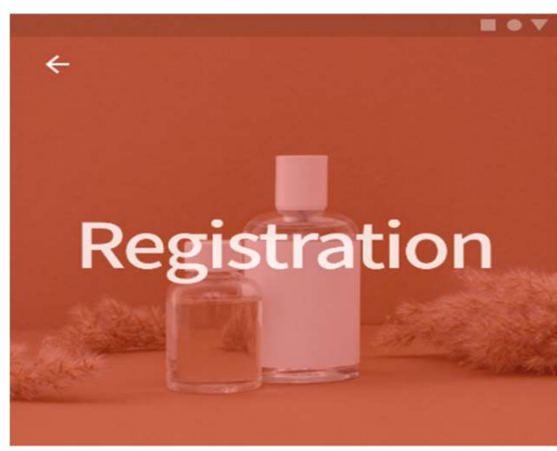

This product is registered by another purchaser. Please check the product information below and contact the person who purchased the product after reporting.

Product Distribution Information
b Purchase Customer
س్, Sales Channel
Logistics transportation

Figure 9. (a) Forgery alert and report, (b) duplication alert and report.

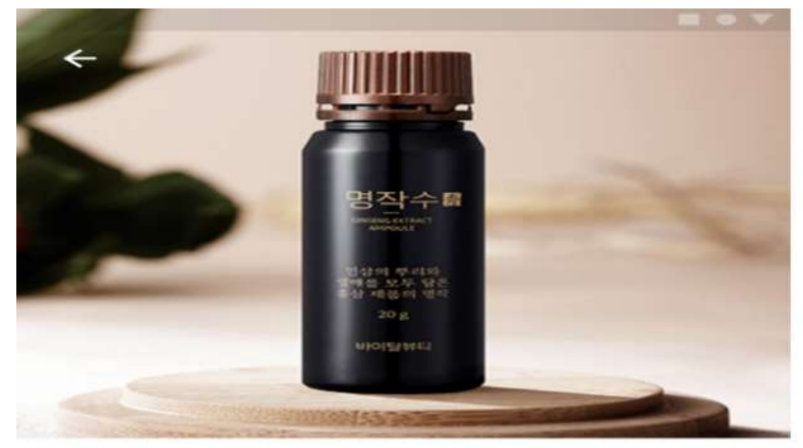

Registration date

28/11/2019

ID

vicj**

Store

Lotte Department Store Gangnam

\section{Vital Beauty Myeongjaksoo}

Vital Beauty

Myungjaksoo is a premium red ginseng ampoule that contains the roots and fruits of ginseng. Restore the original body's vital power and get back to us liveliness health from a masterpiece of red ginseng products with the energy and vitality of the sky and the earth.
Test Information

All ingredients

Vital Beauty Myeongjaksoo

Pesticide residue test

36 out of 36 inspection items passec

Raw material receipt inspection

12 out of 12 inspection items passed

Shipment inspection

13 out of 13 inspection items passed

Product Distribution Information

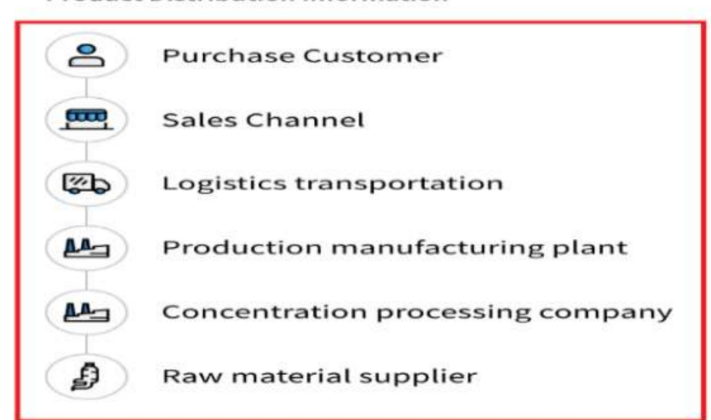

Figure 10. Detailed and comprehensive product information, from raw material to customer purchase. 


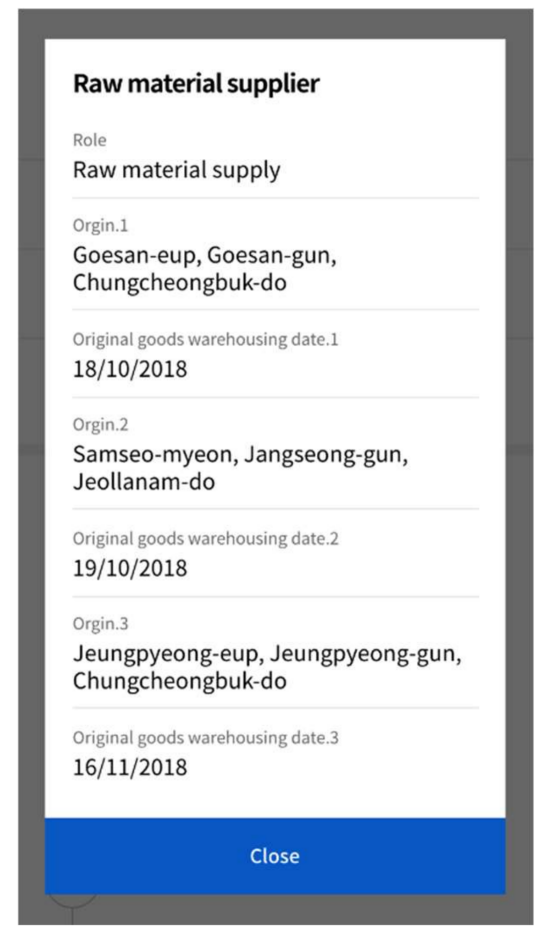

(a)

\begin{tabular}{|lr}
\hline$\leftarrow$ Shipment inspection & \\
\hline Quality & tested \\
\hline Scent & tested \\
\hline Usability & tested \\
\hline $\mathrm{pH}$ & $\mathrm{N} / \mathrm{A}$ \\
\hline $\mathrm{pH}$ & 0.911 \\
\hline Microorganisms (bacteria) & No detected \\
\hline Hardness & $\mathrm{N} / \mathrm{A}$ \\
\hline Content test(Adenosine) & $\mathrm{N} / \mathrm{A}$ \\
\hline Conformity test & $\mathrm{N} / \mathrm{A}$ \\
\hline Content test (Nlacinamide) & $\mathrm{N} / \mathrm{A}$ \\
\hline Conformity test & $\mathrm{N} / \mathrm{A}$ \\
\hline Capacity & $182.2(\mathrm{~g})$ \\
\hline Notation & tested \\
\hline
\end{tabular}

(d)

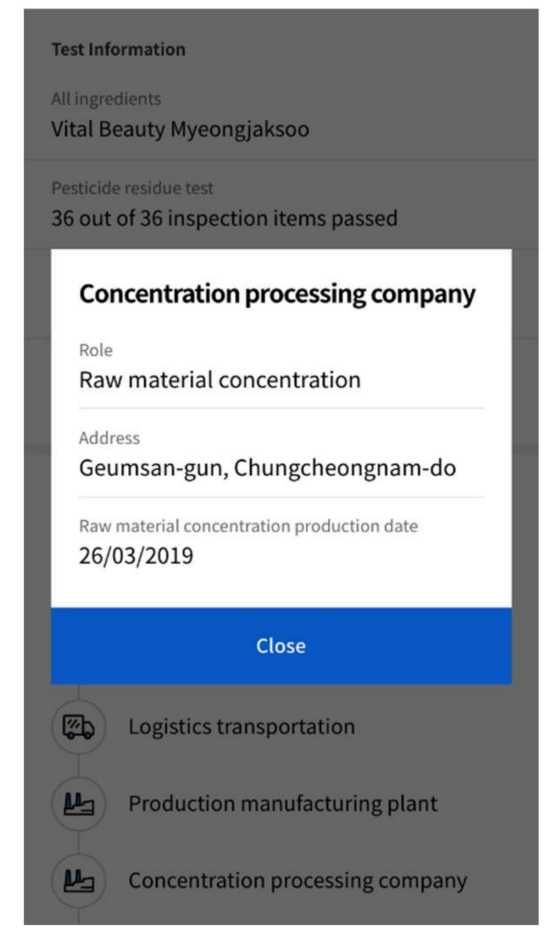

(b)

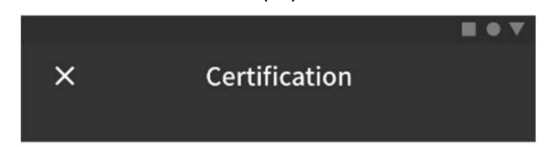

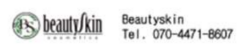

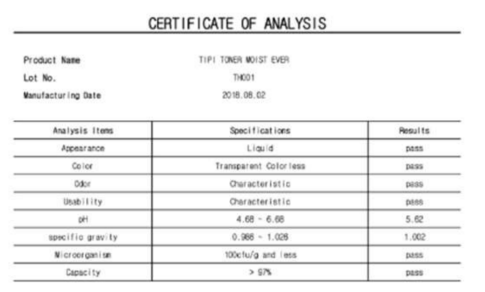

$\mu_{\exists} \quad$ Production manufacturing plant

щ Concentration processing company

(c)
Production manufacturing

Address

37, Gajangsaneopdong-ro, Osan-si,

Gyeonggi-do

Raw material warehousing date

$29 / 03 / 2019$

Date of Manufacture

$22 / 07 / 2019$

Packing date

$29 / 08 / 2019$

\section{Close}

\section{Production manufacturing plant}

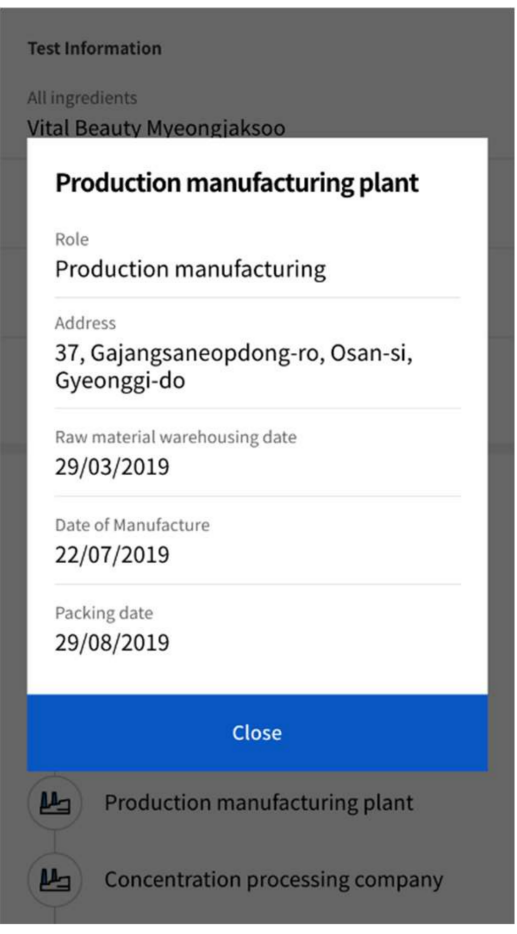




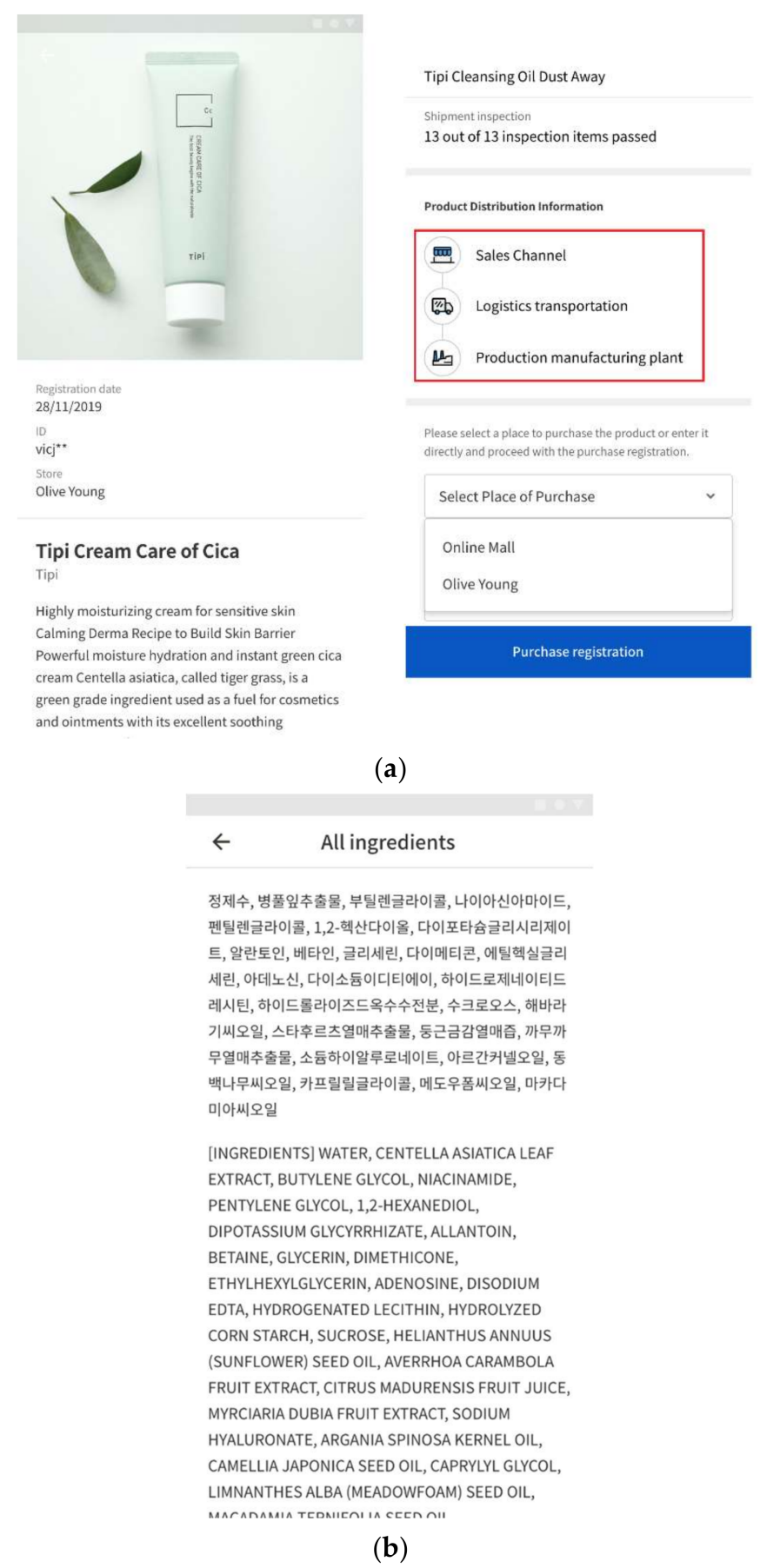

Figure 12. Detailed and comprehensive product information (cosmetics); (a) from manufacturing plant to logistics and sales information, (b) ingredient information.

\section{Implications and Limitations}

Ever since Blockchain's strong traceability and decentralization features have been exploited by the finance industry [66], academic and business experiments have increased for the purpose of finding anti-counterfeiting and forgery solutions in a variety of industries $[45,47,52,57,65,68,70,71]$. Like many prior studies, it is argued that our research and the pilot test verified that Blockchain, supplemented with other technologies such as secured QR [70], can be an effective anti-counterfeiting solution by performing small scale but end-to-end pilot tests.

In the pilot test, various Blockchain platforms were considered-HyperLedger, Sawtooth, Ethereum Private chain, JD chain (DBFT-based self-construction), and Hyperledger 
Fabric were taken into consideration, and we tried to establish a secure and flexible API server. In spite of many benefits of having an API server, there are several disadvantages. One of them is that management complexity increases as the number of nodes increases. When the size of the SCM increases as new suppliers participate in the SCM, managing the cost of the API Sever may rise, too. It is also noted that linkage between different Blockchain platforms via APIs can induce security issues because API servers are frequently the targets of cyber-attacks. From this perspective, ledger-level linkage is mentioned as the best option.

In real-world applications, however, linking ledgers may not be a viable solution, especially when it comes to cross-border e-commerce transactions involving multiple countries, because each country has its own data standard, laws, and guidelines. In addition, the protocol formats adopted by individual firms are all different. Ledger-level interface also would require the standardization of data and protocols at every level and can induce serious cost-efficiency problems. Even though a ledger-level linkage between Hyperledger Fabric and Ethereum was recently tested, Samsung NexLedger and LG Monachain, both of them are customized based on Hyperledger Fabric, and can rarely interface on the leger level once small changes in the protocols of each platform happen.

While the Blockchain in Transport Alliance (BITA) addresses the issue, with more than 200 companies around the world participating ledger-level linkage pilots, it is argued that the API server is a practical option for now because inconsistencies in protocols, consensus algorithms, and data formats can be handled via API server. In addition, expansion to larger-scale tests and real business applications becomes a lot easier when connecting heterogeneous Blockchain platforms in cross-border environments.

However, it is undeniable that attacks on APIs are serious and secure data interfaces among heterogeneous systems still need to be guaranteed. In order to deal with this issue tentatively, the API, Middle Receiver, as a security watchdog has a function of periodically and randomly checking the consistency of the interfacing data. Random checking can reduce system overload, while at the same time keeping the proper frequency of security checks. The faster the cycle, the larger the number of random data to be searched. Higher consistency checks will cause a higher system load, so it is important to select an appropriate period and data quantity. In future research, it will be intended to perform more optimization experiments to determine the best combinations of search cycle and random check data quantity under various control variables including security level, data consistency, and system resources.

\section{Conclusions}

Many business models in the Internet era still rely on information asymmetry and according to uncertainty. Some try to manipulate the discrepancies on purpose in order to get profits. As the intact trades are common, trust is more significant because we heavily rely on the given information by other parties before we make decision and spend our resources. The situations are the same for retail platforms, manufacturing firms, and end-customers. In terms of e-commerce transactions, the lack of traceability and openness of information frequently result in costs of firms' reputation, customers' money, and social trust. From this perspective, our experiment contributes to verifying that "technology innovation is beneficial for solving social challenges including information asymmetry and uncertainty in implementing GSCM". It is proven that the pilot system based on Blockchain reinforces traceability and sharing of information, thus fabricated false information and counterfeiting have little place from the beginning in transactions of cyberworld. E-commerce stakeholders can safely share detailed information, and end-customers, the weakest participants of transactions, can avoid losses coming from information asymmetry and uncertainty. Although barriers to adoption [62] and technological limitations [63] still exist, it is beneficial for the society to further adopt and utilize technology innovation such as Blockchain-based traceability. Many researchers in academia and industry have so far argued that utilization of innovation such as Blockchain's traceability and decentralization are effective and useful for solving practical issues and we added further empirical evidence. 
Since technology innovation and applications are beneficial for economic and social values, we would like to ask governments to fund Blockchain projects, in addition to encourage academia and businesses actively to be engaged in those experiments regardless of the size and potential benefits.

The results of the pilot test showed that it is possible for all of the participants in a supply chain, including overseas end-customers, to securely share comprehensive product information, from raw materials to shipment certificates. As a result, end-customers themselves can differentiate and report counterfeits before those fallacy behaviors become rampant on selling platforms. Our systemic methodology is only one of many approaches and we believe that there are innovative ways to resolve information uncertainty and asymmetry.

Our experiment is a technological feasibility test performed at a small scale. Experts say that Blockchain still has a long way to go to provide advance performance in terms of latency, throughput, and scalability. The efficiency of Blockchain significantly depends on the scalability issues. In the short term, it is not suitable for real-time payment (payment) services due to the inherent problem of low transaction processing rate (TPS); thus selective applications are required according to transaction features such as service levels and methods. Currently, there are offline solutions such as Raiden Network, which distributes transactions that flow to the Mainnet. In the long run, as the development of Blockchain technology speeds up, the scalability will be resolved and be used for real-time payments.

In the pilot, it was attempted to implement 300 TPS with a small number of nodes. Since legacy credit-card systems handle 5000 transactions per second on average, it will be necessary to scale up the system to test feasibility in a real business application. At the same time, the system configuration should be cost efficient and interoperable with a variety of legacy systems that stakeholders are already used to. In this pilot, above all it we aimed for the best trade-off between operating cost and system performance.

In the real world, costs, including those of the system and management, must be counterbalanced with the benefits of adoption [71], and therefore it is important for academia and businesses to repeat pilot tests, regardless of scale.

Currently, it is planned to perform feasibility testing at a business scale, which is expected to be a huge and complicated project. In an actual cross-border business environment, a variety of selling firms will register their products on the Blockchain system, so that huge volumes of purchasers can simultaneously scan QR codes on online screens and mobile phones to query product information and distribution history, to filter out fakes.

In order to evaluate business scale feasibility, the cross-border traceability system should be flexible and be able to accommodate link data exchanges with a variety of types of overseas e-commerce platforms, to monitor inventories in real time to manage each product inventory, and to interoperate with the company logistics and distribution systems in the departure, transit, and destination countries. In addition, to establish a cross-border traceability system it will also be crucial to review cross-border regulations and institutions among countries, involving customs offices.

Author Contributions: Conceptualization, H.L.; methodology, H.L.; software, C.Y.; validation, H.L.; formal analysis C.Y. and his company (Blockodyssey) investigation, C.Y. and his company (Blockodyssey); resources, MOTIE (KEIT, OSP); data curation, C.Y. and his company (Blockodyssey); writing-original draft preparation, H.L.; writing-review and editing, H.L.; visualization, H.L.; supervision, H.L.; project administration C.Y.; funding acquisition, C.Y. All authors have read and agreed to the published version of the manuscript.

Funding: The pilot project was funded by OSP (Office of Strategic R\&D Planning) under KEIT (Korea Evaluation Institute of Industrial Technology).

Conflicts of Interest: The authors declare no conflict of interest. 


\section{References}

1. Yoo, M.; Won, Y. A Study on the Transparent Price Tracing System in Supply Chain Management Based on Blockchain. Sustainability 2018, 10, 4037. [CrossRef]

2. Martinsen, U.; Björklund, M. Matches and Gaps in the Green Logistics Market. Int. J. Phys. Distrib. Logist. Manag. 2012, 42, 562-583. [CrossRef]

3. Lambert, D.M.; Cooper, M.C. Issues in Supply Chain Management. Ind. Mark. Manag. 2000, 29, 65-83. [CrossRef]

4. Qu, T.; Yang, H.D.; Huang, G.Q.; Zhang, Y.F.; Luo, H.; Qin, W. A Case of Implementing RFID-Based Real-Time Shop-Floor Material Management for Household Electrical Appliance Manufacturers. J. Intell. Manuf. 2012, 23, 2343-2356. [CrossRef]

5. Tan, B.Q.; Wang, F.; Liu, J.; Kang, K.; Costa, F. A Blockchain-Based Framework for Green Logistics in Supply Chains. Sustainability 2020, 12, 4656. [CrossRef]

6. Zheng, X.; Zhu, S.; Lin, Z. Capturing the Essence of Word-of-Mouth for Social Commerce: Assessing the Quality of Online e-Commerce Reviews by a Semi-Supervised Approach. Decis. Support Syst. 2013, 56, 211-222. [CrossRef]

7. Nikolakis, W.; John, L.; Krishnan, H. How Blockchain Can Shape Sustainable Global Value Chains: An Evidence, Verifiability, and Enforceability (EVE) Framework. Sustainability 2018, 10, 3926. [CrossRef]

8. Caldarelli, G.; Rossignoli, C.; Zardini, A. Overcoming the Blockchain Oracle Problem in the Traceability of Non-Fungible Products. Sustainability 2020, 12, 2391. [CrossRef]

9. Prashar, D.; Jha, N.; Jha, S.; Lee, Y.; Joshi, G.P. Blockchain-Based Traceability and Visibility for Agricultural Products: A Decentralized Way of Ensuring Food Safety in India. Sustainability 2020, 12, 3497. [CrossRef]

10. Chang, S.E.; Luo, H.L.; Chen, Y. Blockchain-Enabled Trade Finance Innovation: A Potential Paradigm Shift on Using Letter of Credit. Sustainability 2019, 12, 188. [CrossRef]

11. Iansiti, M.; Lakhani, K.R. The Truth About Blockchain. Harv. Bus. Rev. 2017, 95, 119-127.

12. Peter, H. Lewis Attention Shoppers: Internet is Open. Available online: https://www.nytimes.com/1994/08/12/business/ attention-shoppers-internet-is-open.html (accessed on 12 June 2020).

13. Babenko, V.; Kulczyk, Z.; Perevosova, I.; Syniavska, O.; Davydova, O. Factors of the Development of International E-Commerce under the Conditions of Globalization. SHS Web Conf. 2019, 65, 04016. [CrossRef]

14. Retail E-Commerce Sales Worldwide from 2014 to 2023. Available online: https://www.statista.com/statistics/379046 / worldwide-retail-e-commerce-sales / (accessed on 5 January 2021).

15. China Ecommerce 2020. Available online: https://www.emarketer.com/content/china-ecommerce-2020 (accessed on 5 January 2021).

16. Ding, F.; Huo, J.; Campos, J.K. The Development of Cross Border E-Commerce. In Proceedings of the International Conference on Transformations and Innovations in Management, Shanghai, China, 9-10 September 2017; Atlantis Press: Shanghai, China.

17. Chen, L. Developing Asia in the Era of Cross-Border E-Commerce. Available online: https://www.eria.org/ERIA-DP-2017-11.pdf (accessed on 5 January 2021).

18. Gomez-Herrera, E.; Martens, B.; Turlea, G. The Drivers and Impediments for Cross-Border e-Commerce in the EU. Inf. Econ. Policy 2014, 28, 83-96. [CrossRef]

19. Wang, J. Opportunities and Challenges of International E-Commerce in the Pilot Areas of China. Int. J. Mark. Stud. 2014, 6, 141. [CrossRef]

20. SCMP Supply Chain Management Definitions and Glossary. Available online: https://cscmp.org/CSCMP/Educate/SCM_ Definitions_and_Glossary_of_Terms.aspx (accessed on 5 January 2021).

21. Webster, F.E. The Changing Role of Marketing in the Corporation. J. Mark. 1992, 56, 1-17. [CrossRef]

22. Hervani, A.A.; Helms, M.M.; Sarkis, J. Performance Measurement for Green Supply Chain Management. Benchmarking Int. J. 2005, 12, 330-353. [CrossRef]

23. Lim, S.-J.; Phillips, J. Embedding CSR Values: The Global Footwear Industry's Evolving Governance Structure. J. Bus. Ethics 2008, 81, 143-156. [CrossRef]

24. Maloni, M.J.; Brown, M.E. Corporate Social Responsibility in the Supply Chain: An Application in the Food Industry. J. Bus. Ethics 2006, 68, 35-52. [CrossRef]

25. Khan, S.A.R.; Qianli, D. Impact of Green Supply Chain Management Practices on Firms' Performance: An Empirical Study from the Perspective of Pakistan. Environ. Sci. Pollut. Res. 2017, 24, 16829-16844. [CrossRef] [PubMed]

26. King, A.A.; Lenox, M.J. Lean and green? An empirical examination of the relationship between lean production and environmental performance. Prod. Oper. Manag. 2001, 10, 244-256. [CrossRef]

27. Sarkis, J.; Rasheed, A. Greening the Manufacturing Function. Bus. Horiz. 1995, 38, 17-27. [CrossRef]

28. Allenby, B. Supporting Environmental Quality: Developing an Infrastructure for Design. Environ. Qual. Manag. 1993, 2, 303-308. [CrossRef]

29. Klassen, R.D.; McLaughlin, C.P. The Impact of Environmental Management on Firm Performance. Manag. Sci. 1996, 42, 1199-1214. [CrossRef]

30. Yu, Z.; Golpîra, H.; Khan, S.A.R. The Impact of GSCM on Manufacturing Enterprise's Performance. J. Adv. Manuf. Syst. 2018, 17, 445-459. [CrossRef]

31. Handfield, R.; Walton, S.V.; Sroufe, R.; Melnyk, S.A. Applying Environmental Criteria to Supplier Assessment: A Study in the Application of the Analytical Hierarchy Process. Eur. J. Oper. Res. 2002, 141, 70-87. [CrossRef] 
32. Kumar, A.; Jain, V.; Kumar, S. A Comprehensive Environment Friendly Approach for Supplier Selection. Omega 2014, 42, 109-123. [CrossRef]

33. Theyel, G. Customer and Supplier Relations for Environmental Performance. In Greening the Supply Chain; Springer: London, UK, 2006; pp. 139-149.

34. Smith, K.T. An Examination of Marketing Techniques that Influence Millennials' Perceptions of Whether a Product is Environmentally Friendly. J. Strateg. Mark. 2010, 18, 437-450. [CrossRef]

35. Mamic, I. Managing Global Supply Chain: The Sports Footwear, Apparel and Retail Sectors. J. Bus. Ethics 2005, 59, 81-100. [CrossRef]

36. Min, H.; Galle, W.P. Green Purchasing Strategies: Trends and Implications. Int. J. Purch. Mater. Manag. 1997, 33, 10-17. [CrossRef]

37. Choi, D.; Hwang, T. The Impact of Green Supply Chain Management Practices on Firm Performance: The Role of Collaborative Capability. Oper. Manag. Res. 2015, 8, 69-83. [CrossRef]

38. Rao, P.; Holt, D. Do Green Supply Chains Lead to Competitiveness and Economic Performance? Int. J. Oper. Prod. Manag. 2005, 25, 898-916. [CrossRef]

39. Green Gold: How Sustainability Became Big Businessforconsumer Brands 2020. Available online: https://www.ft.com/content/ ce523ca1-c8c2-43e7-86ad-ffa5d6605d2c (accessed on 14 January 2021).

40. Srivastava, S.K. Green Supply-Chain Management: A State-of-the-Art Literature Review. Int. J. Manag. Rev. 2007, 9, 53-80. [CrossRef]

41. Rivoli, P. Labor Standards in the Global Economy: Issues for Investors. J. Bus. Ethics 2003, 43, 223-232. [CrossRef]

42. Gleim, M.R.; Smith, J.S.; Andrews, D.; Cronin, J.J. Against the Green: A Multi-Method Examination of the Barriers to Green Consumption. J. Retail. 2013, 89, 44-61. [CrossRef]

43. CNBC DISRUPTOR 50 Coupang, a SoftBank-Backed Start-up, is Crushing Amazon to Become South Korea's Biggest Online Retailer 2020. Available online: https://www.cnbc.com/2020/06/16/coupang-crushed-amazon-to-become-south-koreasbiggest-online-retailer.html (accessed on 14 January 2021).

44. Gaur, V.; Gaiha, A. Havard Business Review; Harvard Business Publishing, Brighton, Massachusetts, USA. May 2020. Available online: https://hbr.org/2020/05/building-a-transparent-supply-chain (accessed on 14 January 2021).

45. Lee, D. Thousands of Fraudsters are Selling via Shopify, Analysis Finds 2020. Available online: https://www.ft.com/content/02 80592d-0adf-4dcb-a831-4f8a85f414bc (accessed on 14 January 2021).

46. Kouhizadeh, M.; Sarkis, J. Blockchain Practices, Potentials, and Perspectives in Greening Supply Chains. Sustainability 2018, 10, 3652. [CrossRef]

47. Bumblauskas, D.; Mann, A.; Dugan, B.; Rittmer, J. A Blockchain use Case in Food Distribution: Do You Know Where Your Food has been? Int. J. Inf. Manag. 2020, 52, 102008. [CrossRef]

48. Zhu, Q.; Sarkis, J.; Lai, K. Choosing the Right Approach to Green Your Supply Chains. Mod. Supply Chain Res. Appl. 2019, 1, 54-67. [CrossRef]

49. Haq, I.; Muselemu, O. Blockchain Technology in Pharmaceutical Industry to Prevent Counterfeit Drugs. Int. J. Comput. Appl. 2018, 180, 8-12. [CrossRef]

50. Hastig, G.M.; Sodhi, M.S. Blockchain for Supply Chain Traceability: Business Requirements and Critical Success Factors. Prod. Oper. Manag. 2020, 29, 935-954. [CrossRef]

51. Mettler, M. Blockchain Technology in Healthcare: The Revolution Starts Here. In Proceedings of the 2016 IEEE 18 th International Conference on e-Health Networking, Applications and Services (Healthcom), Munich, Germany, 14-16 September 2016; IEEE: Munich, Germany; pp. 1-3.

52. Olk, P.; West, J. The Relationship of Industry Structure to Open Innovation: Cooperative Value Creation in Pharmaceutical Consortia. RD Manag. 2020, 50, 116-135. [CrossRef]

53. Kennedy, Z.C.; Stephenson, D.E.; Christ, J.F.; Pope, T.R.; Arey, B.W.; Barrett, C.A.; Warner, M.G. Enhanced Anti-Counterfeiting Measures for Additive Manufacturing: Coupling Lanthanide Nanomaterial Chemical Signatures with Blockchain Technology. J. Mater. Chem. C 2017, 5, 9570-9578. [CrossRef]

54. Woodside, A.G.; Fine, M.B. Sustainable Fashion Themes in Luxury Brand Storytelling: The Sustainability Fashion Research Grid. J. Glob. Fash. Mark. 2019, 10, 111-128. [CrossRef]

55. Crosby, M.; Pattanayak, P.; Verma, S.; Kalyanaraman, V. BlockChain Technology: Beyond Bitcoin. Appl. Innov. 2016,2 , 71.

56. Hsu, C.-S.; Tu, S.-F.; Huang, Z.-J. Design of an E-Voucher System for Supporting Social Welfare using Blockchain Technology. Sustainability 2020, 12, 3362. [CrossRef]

57. Nam, S. How Much are Insurance Consumers Willing to Pay for Blockchain and Smart Contracts? A Contingent Valuation Study. Sustainability 2018, 10, 4332. [CrossRef]

58. Frizzo-Barker, J.; Chow-White, P.A.; Adams, P.R.; Mentanko, J.; Ha, D.; Green, S. Blockchain as a Disruptive Technology for Business: A Systematic Review. Int. J. Inf. Manag. 2020, 51, 102029. [CrossRef]

59. Zheng, Z.; Xie, S.; Dai, H.; Chen, X.; Wang, H. An Overview of Blockchain Technology: Architecture, Consensus, and Future Trends. In Proceedings of the 2017 IEEE International Congress on Big Data (BigData Congress), Honolulu, HI, USA, 25-30 June 2017; IEEE: Honolulu, HI, USA; pp. 557-564.

60. Olleros, F.; Zhegu, M. Research Handbook on Digital Transformations; Edward Elgar Publishing: Cheltenham, UK/Northampton, MA, USA, 2016; ISBN 978-1-78471-776-6. 
61. Tapscott, A.; Tapscott, D. How Blockchain is Changing Finance. Harv. Bus. Rev. 2017, 1, 2-5.

62. Chen, L.; Xu, L.; Shah, N.; Gao, Z.; Lu, Y.; Shi, W. On Security Analysis of Proof-of-Elapsed-Time (PoET). In International Symposium on Stabilization, Safety, and Security of Distributed Systems; Springer: Cham, Switzerland, 2017.

63. Paliwal, V.; Chandra, S.; Sharma, S. Blockchain Technology for Sustainable Supply Chain Management: A Systematic Literature Review and a Classification Framework. Sustainability 2020, 12, 7638. [CrossRef]

64. Christidis, K.; Devetsikiotis, M. Blockchains and Smart Contracts for the Internet of Things. IEEE Access 2016, 4, 2292-2303. [CrossRef]

65. Pournader, M.; Shi, Y.; Seuring, S.; Koh, S.C.L. Blockchain Applications in Supply Chains, Transport and Logistics: A Systematic Review of the Literature. Int. J. Prod. Res. 2020, 58, 2063-2081. [CrossRef]

66. Sikorski, J.J.; Haughton, J.; Kraft, M. Blockchain Technology in the Chemical Industry: Machine-to-Machine Electricity Market. Appl. Energy 2017, 195, 234-246. [CrossRef]

67. Cousins, P.D.; Lawson, B.; Petersen, K.J.; Fugate, B. Investigating Green Supply Chain Management Practices and Performance: The Moderating Roles of Supply Chain Ecocentricity and Traceability. Int. J. Oper. Prod. Manag. 2019, 39, 767-786. [CrossRef]

68. Lee, H.; Yeon, C. Research on How to Prevent Online Counterfeiting with Blockchain-Based Cross Border Data Sharing. In Proceedings of the 2020 International Conference on Information and Communication Technology Convergence (ICTC), Jeju, Korea, 21-23 October 2020; IEEE: Jeju, Korea; pp. 1940-1945.

69. Liao, K.-C.; Lee, W.-H. A Novel User Authentication Scheme Based on QR-Code. J. Netw. 2010, 5, 937-941. [CrossRef]

70. Mirabelli, G.; Solina, V. Blockchain and Agricultural Supply Chains Traceability: Research Trends and Future Challenges. Procedia Manuf. 2020, 42, 414-421. [CrossRef]

71. Tian, F. An Agri-Food Supply Chain Traceability System for China Based on RFID \& Blockchain Technology. In Proceedings of the 2016 13th International Conference on Service Systems and Service Management (ICSSSM), Kunming, China, 24-26 June 2016; IEEE: Kunming, China; pp. 1-6. 